\title{
Modelo do processo de ação fiscal de segurança e saúde do trabalho na construção de edificações
}

\author{
Model of the labour occupational safety and health \\ inspection process in building construction
}

\section{Didier Cardoso Silva Júnior Fabrício Borges Cambraia}

\begin{abstract}
Resumo
$\mathbf{M}$

uitos esforços pela redução dastretanto o serviço estatal de fiscalização do cumprimento das legislações de segurança e saúde na construção de edificações seja considerado como um indutor para introdução de mudanças, seus processos operacionais pouco conhecidos. Este artigo objetiva a construção de um modelo deste processo particular de ação fiscal. Para tanto, foram realizadas entrevistas com agentes de inspeção do trabalho, gerentes de segurança e gerentes de obra, análise de documentos e acompanhamento prático de ações fiscais. Após a produção de uma versão inicial, o modelo foi revisado por um conjunto de agentes fiscais e os gerentes das empresas. $\mathrm{O}$ modelo construído é graficamente representado por um fluxograma do processo que descreve, em especial, um ciclo de ação fiscal, sendo constituído por planejamento das ações fiscais, visita de disparo, inspeção direta no empreendimento, resultados e possibilidade de aplicação dos instrumentos de intervenção, término e fatores favoráveis para abertura de novos ciclos. O modelo proposto tem função de organização e estruturação, embora seja limitado em descrever a variabilidade real que um ciclo fiscal pode apresentar.

Palavras-chave: Segurança e Saúde. Fiscalização. Inspeção do trabalho. Acidentes. Construção civil.

Didier Cardoso Silva Júnior Universidade Federal de Sergipe São Cristóvão - SE - Brasil

Fabrício Borges Cambraia Universidade Federal de Sergipe São Cristóvão - SE - Brasil

Recebido em 01/04/13 Aceito em 02/09/13

\section{Abstract}

Many efforts to reduce occupational injury rates use the State intervention as a guide for the policies and actions of different organizations involved in accident prevention. However, although the state inspection services regarding the implementation of occupational safety and health regulations can be considered as a driver for introducing changes, not much is known about the operational processes involved. This article aims to devise a model of that particular inspection process. The main sources of evidence adopted were interviews with government inspectors, safety managers and site managers from construction companies, as well as a document analysis and on-site observation of inspections. After the production of the initial version, the model was reviewed by a group of inspectors and managers. The model is represented as a flowchart that contains an inspection cycle, which consists of: producing an inspection plan, preliminary visit, direct inspection at the worksite, results and possibility of applying the intervention tools, and conclusion and propitious factors for new cycles. The proposed model plays an organizing and structuring role, but it is limited in terms of pointing out the existing variability in the inspection cycle.

Keywords: Health and Safety. Inspection. Labour inspection. Injuries. Construction.
\end{abstract}




\section{Introdução}

À medida que as condições e ambientes de trabalho dispõem de leis e normas compulsórias, o serviço de inspeção encontra sentido no intuito de tornar efetivas as regulamentações. $\mathrm{O}$ trabalho na construção civil é frequentemente caracterizado por condições ambientais precárias e altas taxas de acidentes. Essas razões fazem com que a construção civil seja objeto rotineiro da inspeção do trabalho realizada pela fiscalização estatal e de auditorias a cargo dos próprios empregadores e dos sindicatos, que atuam como intermediários da fiscalização (CARDOSO; LAGE, 2005).

As auditorias são demandadas pelos sindicatos e pelas empresas, geralmente com conhecimento prévio de sua ocorrência, enquanto as ações fiscais são atividades desempenhadas pelo Estado, sem agendamento e conhecimento prévio. No Brasil, o principal órgão estatal de inspeção do trabalho com poder de sanção é o Ministério do Trabalho e Emprego (MTE). As ações fiscais promovidas pelo MTE envolvem duas vertentes principais: uma da legislação trabalhista e outra da legislação de Segurança e Saúde do Trabalho (SST). A Consolidação das Leis do Trabalho (CLT) e as Normas Regulamentadoras (NR) são as principais referências para essas fiscalizações.

A construção civil é regulamentada especialmente pela NR-18. Contudo, o atendimento às regulamentações de SST representa o esforço mínimo direcionado à prevenção de acidentes e doenças ocupacionais, particularmente pela inexistência de estudos que comprovem que seu cumprimento integral seja, isoladamente, suficiente para uma redução significativa e duradoura das taxas de acidentes (SAURIN, 2002). Além disso, diferentes estudos apontam limitações relacionadas às ações fiscais, tanto no serviço prestado pelo Estado quanto no comportamento das empresas e sindicatos.

Saurin, Lantelme e Formoso (2000) e Miranda e Dias (2004), por exemplo, apontam a baixa frequência, abrangência e atuação educativa por parte da fiscalização, além de um quadro funcional reduzido e carente de preparo. Cardoso e Lage (2005), por sua vez, apontam como limitações do processo de fiscalização estatal seu viés subjetivo e a necessidade de se aprimorarem condutas, procedimentos e instrumentos. Além disso, o comportamento de muitas empresas tende a ser reativo, visto que aguardam a presença dos fiscais para adoção das medidas preventivas (SAURIN; LANTELME; FORMOSO, 2000) ou optam racionalmente pelo risco de possíveis sanções (CARDOSO; LAGE, 2005).
Em que pese às limitações apresentadas, o fato é que, se por um lado, o não cumprimento dos requisitos de SST pode aumentar os riscos da ocorrência de acidentes, por outro, pode resultar em penalidades e processos judiciais decorrentes da atuação da fiscalização. Atualmente, diante da ocorrência de acidentes com comprovação de culpa, por exemplo, o Instituto Nacional de Seguro Social (INSS) tem impetrado ações regressivas contra as empresas e buscado o ressarcimento de todas as despesas incorridas (ROCHA; CAMBRAIA; DONALD, 2012).

A efetividade das ações fiscais depende, sobretudo, da estrutura e do desenho dos sistemas nacionais de inspeção do trabalho (CARDOSO; LAGE, 2005). Contudo, a literatura é carente, superficial e fragmentada acerca da estrutura e desenho do processo operacional de inspeção do trabalho adotado no Brasil, especialmente na vertente de SST. Os estudos geralmente focam na efetividade da lei no cotidiano das empresas, como as avaliações de adequação à NR-18 (SAURIN; LANTELME; FORMOSO, 2000) e à NR-7 e NR9 (MIRANDA; DIAS, 2004), como também na avaliação de instrumentos de intervenção aplicados pelos fiscais nas empresas (ROCHA, 2011). O processo de ação fiscal é geralmente utilizado como elemento secundário e explicativo dos resultados desses estudos, embora sem um adequado conhecimento dele.

Nesse cenário, o quadro identificado aponta para a necessidade de estudos que contemplem o processo operacional de ação fiscal de forma sistematizada e estruturada, possibilitando uma melhor compreensão desse processo. Além disso, os atores envolvidos no processo de ação fiscal, apesar de terem individualmente uma noção de suas etapas e interfaces, dispõem de uma visão restrita e fragmentada do mesmo, o que muitas vezes pode resultar em dúvidas e críticas ao serviço estatal por simples desconhecimento. Assim sendo, este artigo objetiva a construção de um modelo do processo operacional de ação fiscal de SST na construção de edificações, contemplando seu funcionamento, principais etapas e interfaces, ações e instrumentos de intervenção.

\section{Estrutura de inspeção do trabalho no Brasil}

A estrutura de inspeção do trabalho no Brasil é baseada na Convenção 81 da Organização Internacional do Trabalho (OIT), que constitui o principal ordenamento internacional que disciplina

30 Silva Júnior, D. C.; Cambraia, F. B. 
esse serviço (MACHADO, 2005). Na estrutura do MTE, a atividade de inspeção do trabalho está vinculada à Secretaria de Inspeção do Trabalho (SIT), que dispõe de competências tais como o poder de fazer cumprir as legislações do trabalho e a elaboração do planejamento estratégico de suas ações em âmbito nacional (CARDOSO; LAGE, 2005). A SIT é subdividida em dois departamentos, um de fiscalização da legislação trabalhista e outro de SST (BRASIL, 2004).

As atividades planejadas e normalizadas pela SIT são executadas e administradas pelas Superintendências Regionais do Trabalho e Emprego (SRTE), que são órgãos descentralizados e com representações em todos os estados da federação. Internamente às SRTE, há uma área específica responsável pelas inspeções do trabalho, que contemplam seções ou núcleos particulares, que tratam das fiscalizações do trabalho e da SST (BRASIL, 2010a).

Além disso, nas SRTE estão lotados os agentes de inspeção do trabalho (AIT), que executam as fiscalizações e outras atividades pertinentes às relações de trabalho (MACHADO, 2005). Entre as competências dos AIT estão a identificação e a caracterização de risco grave e iminente (RGI). O controle de situações de RGI é preconizado pela Convenção 81 da OIT, sendo disseminado entre os países que a ratificaram, embora com grande variabilidade quando de sua aplicação (BRASIL, 2010b). Em parte, essa variabilidade se deve à falta ou ao viés subjetivo do conceito, competindo aos AIT sua identificação e tomada de ações administrativas, geralmente de caráter imediato.

No Brasil, segundo a NR-3 (BRASIL, 2011a), risco grave e iminente é definido como "[...] toda condição ou situação de trabalho que possa causar acidente ou doença relacionada ao trabalho com lesão grave à integridade física do trabalhador [...]". O risco será iminente quando a exposição do trabalhador for direta, imediata, ou num futuro muito próximo, e a lesão grave não necessariamente deverá se manifestar imediatamente, podendo ser imediata ou mediata (BRASIL, 2010b). O entendimento de que a lesão pode ser mediata alinha-se com a visão de RGI da legislação norte-americana (UNITED..., 1970), pois se consideram não apenas os riscos de acidentes, mas também aqueles associados às doenças ocupacionais. Apesar de tais entendimentos e alguns pontos de consenso, na prática a avaliação do RGI é dependente da visão de cada AIT. Contudo, o dever e poder de interpretação e ação atribuído aos AIT diante das situações de RGI muitas vezes gera polêmica e ações judiciais (BRASIL, 2010b), particularmente quando os atores envolvidos negligenciam entendimentos de que a gestão do risco, por exemplo, pode ser socialmente negociada no contexto específico do problema (SLOVIC, 2001).

A estrutura regimentar da inspeção do trabalho no Brasil está contida, sobretudo, no Regulamento da Inspeção do Trabalho (RIT), publicado em 2002 pelo Decreto 4.552 (BRASIL, 2002). Esse documento apresenta o Sistema Federal de Inspeção do Trabalho (SFIT), que se trata de um banco de dados utilizado na gestão dos serviços de inspeção do trabalho em todo o país. Além dos resultados alcançados nas fiscalizações, no SFIT são lançadas, por exemplo, as ordens de serviços (OS) para os AIT iniciarem os processos de ações fiscais (BRASIL, 2010a).

A Portaria 546, de 2010, é um documento complementar ao RIT, que disciplina a forma de atuação da inspeção do trabalho, a elaboração do planejamento das fiscalizações e a avaliação de desempenho funcional dos AIT, entre outras providências (BRASIL, 2010a). De acordo com a citada portaria, a inspeção do trabalho atua com base no planejamento e na execução dos projetos que a compõem, concebidos por ramos econômicos específicos ou por situações especiais e degradantes de trabalho. A elaboração e a execução dos projetos e ações devem seguir diretrizes e metas de um plano plurianual e as orientações da SIT.

\section{Método de pesquisa}

Este estudo considera um modelo como sendo uma representação idealizada e simplificada da realidade (KRAPAS et al., 1997; VERA, 1983). A representação se caracteriza pela existência de uma estrutura ou elemento gráfico para facilitar $\mathrm{o}$ entendimento do objeto de estudo (MARTINS, 2003). A idealização significa que o modelo não pode ser entendido como a única forma de representação da realidade, à medida que é uma proposição de seus autores (VERA, 1983). Ao ser idealizado, o modelo apresentará limites e validade para certo domínio (KRAPAS et al., 1997). Já a simplificação enfatiza que o modelo não é a realidade, devendo-se entendê-lo como uma realidade em estudo (VERA, 1983).

Martins (2003) destaca que o modelo pode desempenhar uma função organizacional e estrutural, correspondendo à classificação dos elementos da realidade segundo um esquema estruturado e com ordenação lógica. Além disso, esse autor descreve cinco etapas para a construção de modelos:
(a) conceitualização;
(b) modelagem; 
(c) solução encontrada para o modelo;

(d) implementação; e

(e) validação.

$\mathrm{Na}$ etapa de conceitualização buscou-se o referencial teórico por meio de pesquisa bibliográfica, para auxiliar no entendimento do processo de ação físcal. A construção do modelo em si (modelagem) foi possível mediante pesquisa bibliográfica e realização de entrevistas com AIT, engenheiros de segurança e de obra, realizadas entre os meses de maio e julho de 2012, além de análise documental e acompanhamento prático de ações fiscais. Os dados empíricos foram coletados na cidade de Aracaju (SE).

As entrevistas basearam-se em um roteiro semiestruturado, que questionava, principalmente, os critérios para definição das obras a serem fiscalizadas, os procedimentos empregados e o desenvolvimento das ações fiscais até sua finalização. Todas as entrevistas foram gravadas e tiveram duração média de duas horas. Em relação aos AIT, foram cinco entrevistados, sendo quatro ativos na SRTE/SE e outro recentemente aposentado. No período da coleta dos dados, a SRTE/SE dispunha de cinco AIT, que executavam as fiscalizações no campo. Desse total, dois foram entrevistados nessa etapa em função da maior experiência em ações fiscais na construção civil comparativamente aos demais. Um era engenheiro civil e o outro médico, o primeiro com menos e o segundo com mais de 10 anos de serviços prestados ao Estado.

Os outros dois AIT ativos entrevistados (um engenheiro e outro médico) estavam há mais de 20 anos na função e, no período das entrevistas, ambos ocupavam cargos internos de chefia na SRTE/SE. O engenheiro chefiava a seção de fiscalização de SST, e o médico, a seção de fiscalização trabalhista. O quinto AIT entrevistado nessa etapa era um engenheiro civil, aposentado há menos de cinco anos e com vasta experiência em ações fiscais na construção e também em cargos gerenciais na SRTE/SE.

Os engenheiros de segurança e obra entrevistados, por sua vez, foram selecionados em função da experiência em ações fiscais e por atuarem em empresas frequentemente alvo das inspeções do MTE. Foram realizadas cinco entrevistas individuais com engenheiros de segurança, que atuavam em empresas diferentes, e todos apresentavam, no mínimo, oito anos de experiência. As entrevistas com engenheiros de obra também totalizaram cinco, e todos eles já haviam participado ativamente do processo de ação fiscal e possuíam, no mínimo, cinco anos de profissão.

Os documentos analisados foram 12 de autos de infração de cinco diferentes empresas, dois termos de interdição e embargo de diferentes empresas, além de livros de inspeção do trabalho de cinco empresas. Houve ainda o acompanhamento de duas visitas dos AIT em obras de diferentes empresas. A descrição do processo fiscal foi realizada simultaneamente com a coleta dos dados, apoiando-se principalmente na análise dos áudios das entrevistas. Antes de se iniciar a construção gráfica do modelo, teve de se decidir quanto à forma de representação gráfica a ser utilizada. Diante do objetivo da pesquisa, considerou-se adequada a utilização de alguma ferramenta clássica da Engenharia de Processos, optando-se pelo emprego do fluxograma. Após alguns ciclos de proposição e revisão, chegou-se a uma primeira versão do modelo.

Visto que o modelo em construção tem fins, sobretudo, de descrição e estruturação, e, como consequência, de explicação, a etapa de implementação refere-se especialmente à verificação de sua adequação de sentido para os envolvidos no processo. Assim, essa etapa se torna complementar à próxima (validação), sendo tênue o limite entre ambas. Para a adequação de sentido, a versão inicial do modelo foi submetida à apreciação de dois AIT atuantes em fiscalizações de campo. O primeiro, com formação em Direito, não havia participado das entrevistas na etapa de modelagem, e o segundo, com formação em Engenharia Civil, já havia sido entrevistado. Além disso, também participaram da validação quatro engenheiros, sendo dois de segurança e dois de obras. Uma dupla (engenheiros de segurança e de obra) já havia sido entrevistada, e a outra não, mas também apresentava larga experiência no processo investigado. Após esses procedimentos, o modelo inicial sofreu pequenos ajustes, construindo-se a versão final.

\section{Modelo do processo de ação fiscal de SST na construção de edificações}

O modelo do processo de ação fiscal de SST na construção de edificações é apresentado por meio da representação gráfica e da descrição de um ciclo de ação fiscal. O fluxograma da Figura 1 indica os rumos que a fiscalização pode tomar, considerando que o desenrolar do processo depende dos objetivos da ação, que estão vinculados principalmente a sua fonte geradora e às prioridades e visão pessoal de cada AIT, o que

32 Silva Júnior, D. C.; Cambraia, F. B. 
muitas vezes é influenciado por características de sua formação básica e seu conjunto de crenças e valores. $\mathrm{O}$ ciclo de ação fiscal é definido como o conjunto de decisões e ações formais tomadas diretamente pelos AIT responsáveis pela fiscalização nos canteiros, tendo início no recebimento de uma OS e visita à obra, e término com a regularização das inadequações encontradas e/ou com a emissão de autos de infração, caso existam.

Figura 1 - Fluxograma representativo de um ciclo de ação fiscal de SST na construção de edificações

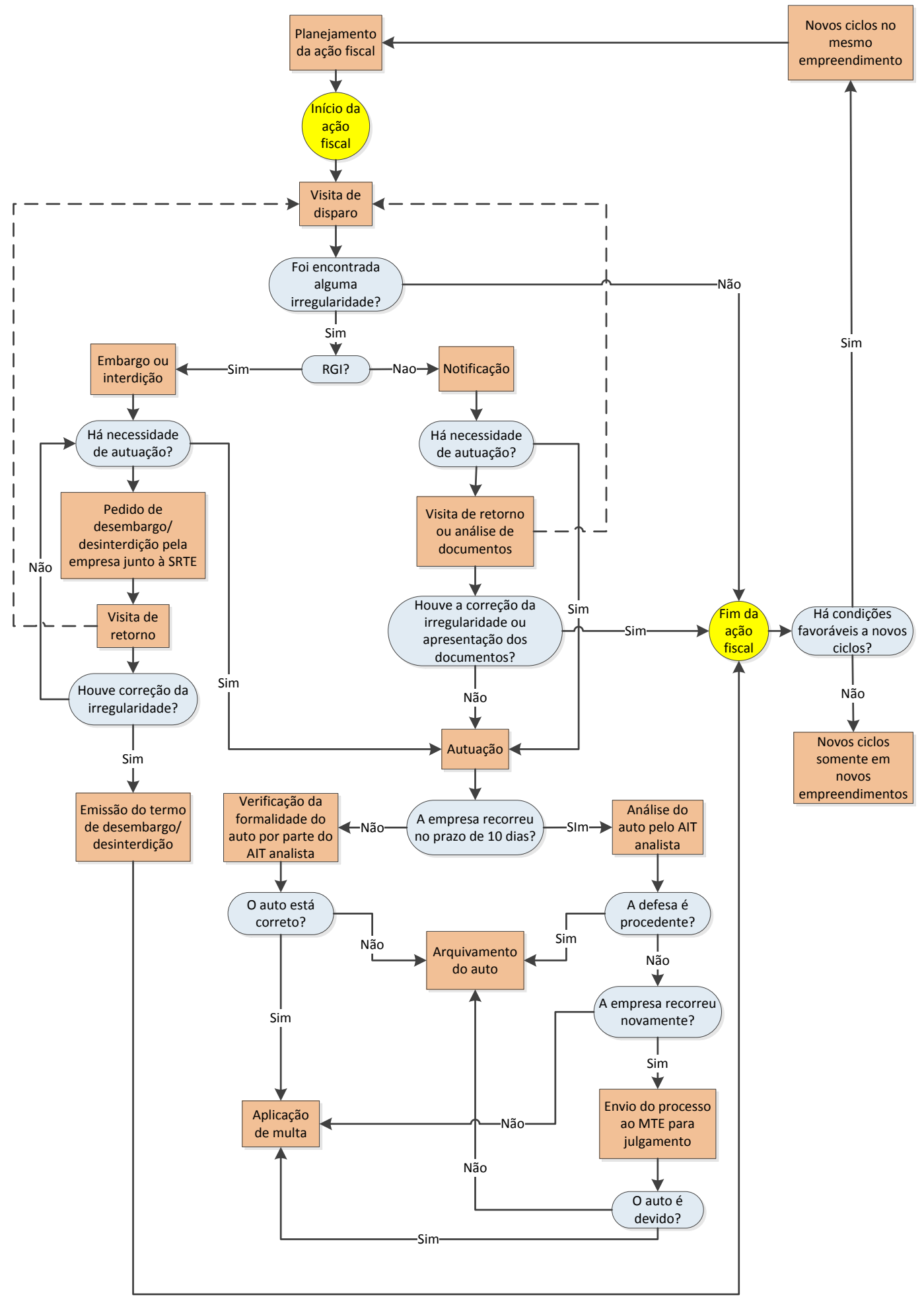




\section{Planejamento das ações fiscais}

As ações fiscais são planejadas a partir de um conjunto de fontes geradoras, que estão ligadas às demandas internas (ao MTE e à SRTE) e externas. As chefias dos núcleos de fiscalização do trabalho e de SST estabelecem, em conjunto, o planejamento das ações fiscais de determinado período. De acordo com os AIT que atuam em cargos gerenciais, os AIT são listados nas ações em função da disponibilidade, buscando-se, na medida do possível, variar os agentes entre as empresas. Além disso, os AIT também são designados visando a atender as metas específicas individuais a eles atribuídas, que são definidas e controladas pelo SIT. Após a definição das ações e dos agentes responsáveis, as chefias emitem OS, via SFIT, responsabilizando os AIT pelas fiscalizações. O estudo identificou, por meio das entrevistas e análises de documentos, seis fontes geradoras, sendo as quatro primeiras de gênese interna, e as outras de origem externa:

(a) Planejamento Estratégico do MTE;

(b) Base de Dados Interna;

(c) Identificação Visual;

(d) Acidentes Graves;

(e) Denúncias; e

(f) Demandas de Outros Órgãos Públicos.

\section{Planejamento estratégico do MTE}

O Planejamento Estratégico do MTE é desmembrado nas SRTE em projetos específicos, como é o caso da construção civil, contemplando metas e objetivos anuais. Para cada um dos projetos é designado um AIT para o papel de coordenador, o qual deve garantir o alinhamento do mesmo com o Planejamento Estratégico do MTE. A partir desses projetos são elaborados planos de ação com metas que visam a, principalmente, fiscalizar um maior número de empresas e atingir um maior número de trabalhadores (principais indicadores quantitativos do MTE). A implicação dessas metas principais é que, geralmente, as empresas ou obras de maior porte tendem a sofrer maior fiscalização, em virtude do maior contingente de trabalhadores. Além disso, nos casos de projetos ou objetivos bem particulares, sejam motivados por problemas específicos ou por alteração da legislação, as empresas e sindicatos são convocados previamente pela SRTE para explicação e difusão das novas exigências. Um exemplo recente citado nas entrevistas, tanto por engenheiros quanto pelos AIT, foi o caso de fiscalizações específicas para verificação das condições de segurança dos elevadores a cabo.

\section{Base de dados interna do MTE}

O SFIT auxilia as SRTE na gestão das inspeções do trabalho, à medida que se pode obter um histórico das empresas passíveis de fiscalização, com informações tais como descrição, frequência ou reincidência de infrações. $\mathrm{O}$ cruzamento dessas informações com as comunicações prévias (CP) à SRTE, que é um documento obrigatório, imposto pela NR-18, antes do início de qualquer atividade de construção, possibilita a priorização das obras a serem fiscalizadas. Busca-se, na medida do possível, que a priorização esteja alinhada com as metas estratégicas contidas no Projeto da Construção Civil.

\section{Identificação visual}

Qualquer AIT pode identificar visualmente obras em execução, tendo o dever de fiscalizar sempre que, ao visualizá-la, identificar principalmente situações que interprete como sendo de RGI. Para isso, os AIT devem solicitar uma Ordem de Serviço Dirigida, para abertura do ciclo fiscal no estabelecimento. Nesses casos, as obras em regiões centrais e rotas bem movimentadas das cidades (avenidas importantes, por exemplo) tendem a ser mais fiscalizadas, pois estão presentes no dia a dia dos AIT, em contraposição às obras em regiões periféricas e de menor trânsito.

\section{Investigação de acidentes}

Apesar da obrigatoriedade da comunicação à SRTE dos acidentes fatais, os AIT podem ter conhecimento deles por outros canais. Diante da ocorrência de óbitos, é realizada a investigação do acidente pelos AIT, em sistema de rodízio entre eles. Dependendo do caso e das conclusões das análises, ações fiscais podem ser planejadas com o intuito de averiguar situações similares em outras empresas. Por exemplo, em 2011, após a queda de um elevador a cabo que resultou em óbito de nove trabalhadores, ocorreram ações fiscais específicas para a averiguação desses equipamentos em todo o território brasileiro. Conforme os AIT, esse tipo de demanda se dá principalmente quando acidentes ocorrem devido à falha de equipamentos, máquinas e proteções coletivas de grande repercussão no meio técnico e social.

\section{Denúncias}

Qualquer cidadão ou órgãos específicos podem denunciar irregularidades no trabalho e, nestes casos, o RIT prevê a apuração imediata da veracidade dos relatos. As denúncias são sigilosas,

34 Silva Júnior, D. C.; Cambraia, F. B. 
e as SRTE disponibilizam canais para isso, seja por contato telefônico ou plantões periódicos. Nas entrevistas com os AIT constatou-se que maioria das denúncias dos trabalhadores refere-se às questões de legislação trabalhista, e os sindicatos se mostram um pouco mais preocupados com a SST. As denúncias podem, inclusive, ter origem nos especialistas de segurança, que muitas vezes não dispõem de condições adequadas de trabalho, como também na comunidade, principalmente de indivíduos que residem nas proximidades das obras.

\section{Demandas de outros órgãos públicos}

Uma ação fiscal também pode ser gerada por demandas de outros órgãos públicos, tais como o Ministério Público do Trabalho (MPT), Instituto Nacional de Seguridade Social (INSS) e Vigilância Sanitária (SILVA; MATTÉ, 2009). Diante de problemas constatados pelos citados órgãos públicos, as SRTE podem ser acionadas por eles, à medida que cabe aos AIT o poder direto de intervenção a qualquer tempo, sem a necessidade de autorizações judiciais específicas.

\section{Visita de disparo}

Dificilmente uma empresa construtora de edificações será fiscalizada em outros estabelecimentos que não sejam as obras, em função da maior incidência de riscos. O ciclo de uma ação fiscal, na prática, tem início com uma visita ao empreendimento objeto da ação, denominada de visita de disparo. Em alguns casos, a fiscalização é realizada por uma dupla de AIT, o que, na visão dos agentes e dos engenheiros entrevistados, contribui para a eficácia da fiscalização, pela possibilidade de ampliação das visões e análise conjunta dos fatos. Geralmente, a visita de disparo é iniciada imediatamente antes do AIT se apresentar no canteiro, pois ele pode reservar um tempo para observação e registro fotográfico ainda na parte externa da obra.

A primeira impressão da obra quanto à organização do canteiro é apontada pelos AIT e engenheiros como de importância fundamental nos resultados da ação fiscal. Segundo um engenheiro, “[...] a organização e limpeza dos canteiros é de fundamental importância. A cara da obra influencia muito, pois dá a primeira impressão ao fiscal [...]". Além disso, a recepção e a atenção dispensada aos AIT também são fatores relevantes na visão dos engenheiros. Nas empresas pequenas geralmente os fiscais são recebidos pelos técnicos de segurança, caso existam, ou pelos mestres de obra. Já nas empresas de maior porte eles são acompanhados quase sempre por profissionais com maior grau de escolaridade, o que facilita o diálogo técnico. Nesse sentido, um engenheiro de segurança declarou que, na matriz de responsabilidades da empresa em que atua, havia uma definição para que a recepção fosse necessariamente realizada pelo engenheiro de segurança ou da obra.

As visitas de disparo, salvo situações bem particulares, são constituídas por inspeções de campo e no escritório das obras. Com a presença de dois agentes, comumente um se encarrega de inspecionar o canteiro, com foco nas questões de SST, e o outro se atém ao escritório, realizando a inspeção documental. Nos casos de visitas individuais, geralmente os AIT optam por iniciar pela inspeção do canteiro. Segundo um deles, por exemplo, com esse procedimento inicial a empresa terá menos tempo de "mascarar" o que realmente está acontecendo. Durante as inspeções é comum os agentes dialogarem informalmente com os trabalhadores para melhor conhecimento da realidade.

Em função da fonte geradora, as visitas podem ser de rotina ou direcionadas. As primeiras ocorrem sem a existência de uma demanda específica e visam a atender as metas estabelecidas nos projetos, utilizando-se da base de dados interna do MTE. Já as segundas são focadas na averiguação de demandas específicas, embora seja obrigação do AIT intervir mediante quaisquer irregularidades. As visitas direcionadas podem ser motivadas por denúncias, demandas externas ou como fruto de lições aprendidas a partir de acidentes.

Diante da variabilidade das demandas e da extensa legislação, inexistem roteiros formais ou ferramentas para guiar as inspeções, tais como listas de verificação, tampouco diretrizes explícitas e formalizadas por parte do MTE. Nas visitas de rotina, o "olhar" do AIT tende a ser bem abrangente, e a ênfase dada varia com a experiência, formação profissional e vieses de cada agente. Um dos AIT relatou que geralmente são focados os itens que já são previamente conhecidos como fonte de irregularidades nas obras. Outro, por sua vez, enfatizou que "[...] é humanamente impossível se olhar tudo [...]", havendo, portanto, maior consideração de alguns itens considerados mais críticos em detrimento de outros. Há certo consenso entre os entrevistados acerca das principais fontes de problemas nas obras, que ocorrem especialmente nas instalações provisórias, nos equipamentos (serra circular, guinchos, elevadores e gruas, por exemplo), nas proteções coletivas (tais como bandejas, fechamentos dos poços dos elevadores e proteções periféricas) e nas instalações elétricas. 
A inspeção de escritório aborda não apenas a documentação das relações de trabalho, mas também a de SST. Contudo, na presença de dois agentes, o responsável pela inspeção do canteiro geralmente também acaba inspecionando a documentação de SST. Não raras vezes os AIT recolhem ou solicitam a entrega de documentos diretamente na SRTE, para análises mais cautelosas ante o ambiente nem sempre propício dos canteiros. Os documentos inicialmente analisados são o Livro de Inspeção e a Comunicação Prévia. Depois disso, analisam-se o PCMAT, PCMSO e PPRA (caso seja aplicável à obra), os projetos de proteções coletivas e laudos técnicos e projetos específicos de equipamentos, por exemplo. Além disso, de acordo com os AIT, um ponto importante da análise documental diz respeito à averiguação da situação das empresas subcontratadas, que, no geral, apresentam um histórico de muitas irregularidades. Cabe enfatizar que toda visita na obra gera um registro no livro de inspeção, que deve ser mantido no estabelecimento e onde são anotadas, por exemplo, as irregularidades encontradas, os prazos concedidos, os autos de infração lavrados, os embargos e interdições.

\section{Resultados da visita de disparo}

Concluída a inspeção na obra tem-se a etapa de resultados. Diante da inexistência de irregularidades, o que, segundo os AIT, é incomum na construção civil, dá-se por encerrado o ciclo fiscal. Já nos casos de irregularidades, os agentes podem aplicar até quatro instrumentos de intervenção:

(a) notificação;

(b) embargo;

(c) interdição; e

(d) autuação.

A utilização desses instrumentos depende da natureza da irregularidade e do viés interpretativo do AIT, podendo implicar a ocorrência de subciclos, que acarretarão novas visitas (de retorno) ao canteiro e/ou ações internas às SRTE/MTE.

A identificação, ou não, de situações interpretadas como de RGI é o principal critério para a seleção do instrumento, podendo haver situações particulares em que serão usados todos os instrumentos simultaneamente. Nas irregularidades em que se entende que não há RGI, geralmente se aplicam notificações e/ou autuações e multas. Diante de RGI, a intervenção frequentemente acontece mediante embargo (paralisação) total ou parcial da obra, interdição de equipamentos e/ou autuações. As visitas de retornos geralmente são direcionadas às situações anteriormente irregulares. Corrigidas as irregularidades e na inexistência de novas inadequações, encaminha-se para o término do ciclo. Mediante novas irregularidades, a visita de retorno ganha características de visita de disparo.

\section{Notificações}

As notificações são necessidades de adequação aos requisitos da legislação, com prazos definidos pelos AIT, envolvendo desde ajustes em instalações até a apresentação ou correção de documentos. Além de seu registro no livro de inspeção, essas infrações são formalizadas por meio da emissão do termo de notificação. Emitido o termo, a empresa deve efetuar as adequações no prazo estipulado, o que será avaliado pelo AIT na visita de retorno. A data dessa visita pode ser agendada ou não pelo AIT. Quando não, a data explicitada no livro torna-se indicativa, e, a partir dela, a visita poderá ocorrer a qualquer tempo. Segundo os entrevistados e os documentos analisados, as notificações referentes às instalações provisórias e apresentação de documentos representam as categorias mais comuns relativas à SST.

Além das notificações oriundas das inspeções de campo, existem também as notificações coletivas. Nesse caso, as empresas são notificadas coletivamente, através do endereçamento de documento oficial pela SRTE, em decorrência de mudanças na legislação ou outras situações particulares. Possuem o mesmo valor legal das notificações individuais, havendo atribuição de prazos e avaliação do cumprimento.

\section{Interdições e embargos}

Em casos de interdições e/ou embargos, verifica-se um subciclo processual com características bem similares, iniciados principalmente após a constatação de situações de RGI. Ambas as intervenções são formalizados através da emissão de um termo, paralisando imediatamente as áreas irregulares. Legalmente, o poder para realizar interdições e embargos é oficialmente do Superintendente Regional de Trabalho e Emprego, embora haja, na prática, a delegação desse serviço aos AIT.

O embargo total acontece comumente em casos de irregularidades de diferentes naturezas, ocorrendo simultaneamente. Contudo, situações relativamente simples, porém nem sempre atendidas, podem gerar um embargo. Exemplo disso foi o relato de um AFT que embargou totalmente a obra de um edifício em que o

36 Silva Júnior, D. C.; Cambraia, F. B. 
bebedouro estava excessivamente distante dos postos de trabalho e inexistia equipamento de transporte vertical de pessoas. Outro AIT ressaltou que não apenas situações de RGI ocasionam embargos, mas também problemas de organização e limpeza da obra, como mostra o fragmento de discurso dele: "[...] se eu chego na obra e não há sanitários suficientes, o refeitório não é adequado, ou seja, não há uma condição boa de higiene para o trabalhador, eu embargo a obra [...]".

No entanto, tanto engenheiros quanto AIT salientaram que as situações com maior frequência de embargos são as referentes aos trabalhos com risco de queda, especialmente ausência ou precariedade nas proteções periféricas, instalações elétricas improvisadas e trabalhos com movimentação de terra, principalmente aberturas de valas e fundações profundas. Quanto às interdições, os equipamentos com maior incidência de paralisação são as bancadas de serra, os andaimes, os elevadores (em particular, os de cabo) e os guinchos de coluna.

Diferentemente das notificações, não há atribuição de prazos para a regularização das inadequações. Concluídas as adequações, a empresa deve entrar com um pedido de desembargo/desinterdição junto à SRTE e aguardar a visita de retorno do AIT. Ao término da visita de retorno, caso as irregulares tenham sido efetivamente sanadas, o AIT emitirá um termo de desembargo/desinterdição. Caso contrário, a área e/ou equipamento continuará paralisado. Além disso, podem ser identificadas novas irregularidades e, dependendo da natureza delas, o AIT aplicará o instrumento de intervenção apropriado, com seus respectivos trâmites processuais. $\mathrm{Na}$ inexistência de detecção de novas irregularidades e havendo conformidade com o exigido, o ciclo de ação fiscal será encerrado.

\section{Autos de infração e multas}

O auto de infração é um instrumento que os AIT podem utilizar sempre que for constatada uma irregularidade. Em que pese à existência de situações em que os autos de infração são corriqueiramente aplicados, tais como nos casos de reincidências e na inexistência de comunicação prévia, muitas vezes a autuação, ou não, dependerá da interpretação dos agentes. Formalmente, o auto de infração é um documento específico, lavrado em três vias, devendo ser assinado e datado pelo empregador ou preposto e pelo ATI responsável pela emissão, contendo, por exemplo, capitulação (artigos, capítulos e incisos específicos da legislação violada), histórico dos fatos e os elementos de convicção (evidências factuais da violação).
Os autos podem ocorrer de forma simultânea à aplicação de notificações e embargos/interdições, abrindo um subciclo processual, que envolve, além do AIT responsável pela emissão, outros AIT que trabalham internamente à SRTE e, em casos extremos, profissionais alocados na sede do MTE. $\mathrm{Na}$ visão de um AIT, não se deve embargar/interditar e autuar a empresa pelo mesmo motivo, pois ela estaria sendo duplamente penalizada. Porém, essa visão não é um senso comum entre os AIT, visto que alguns fazem uso simultâneo dos instrumentos. Nesse sentido, outro AIT considerou que, dependendo do histórico da empresa, ela pode sofrer embargo e autuação, principalmente em casos de resistências às melhorias e reincidências.

Após tomar ciência do auto de infração, a empresa tem dez dias, contados a partir da data de recebimento do documento, para apresentar sua defesa à SRTE. O auto e os documentos de defesa, caso existam, são avaliados por um AIT independente (analista interno), que julga se o auto de infração é devido (procedente) ou não. Nos casos considerados indevidos, os documentos são despachados para arquivamento. Sendo devido, envia-se o auto para o núcleo de Multas e Recursos, que emitirá a multa. Sendo a empresa reincidente, a multa tem seu valor dobrado. Além disso, se o pagamento for efetuado até o prazolimite determinado, nele incidirá um desconto de $50 \%$. Alguns AIT enfatizam o baixo valor das multas, principalmente para empresas de médio e grande porte, considerando que outros instrumentos, tais como os embargos e interdições, apresentam melhor eficácia na indução de melhorias nas empresas.

Nos casos em que a empresa apresenta defesa na SRTE e esta é considerada improcedente, há uma possibilidade de recorrer. Se isso acontecer segundo os prazos legais, o processo será encaminhado, após o cálculo da multa, e julgado na sede do MTE. Nesses casos, a empresa perde o direito ao desconto de $50 \%$ do valor da infração, e a empresa multada deverá depositar em juízo e aguardar o julgamento do caso. Segundo dois AIT, muitas vezes as empresas preferem recorrer ao MTE, pois os prazos de julgamento são longos e os processos acabam sendo arquivados.

\section{Término do ciclo de ação fiscal}

De acordo com o regulamento interno do MTE, um ciclo de ação fiscal deve ter duração máxima de 120 dias. De acordo com um dos AIT entrevistados, "[...] um ciclo de ação fiscal na construção civil dura em média dois meses. Em empresas que prezam pela SST, pode durar menos 
de um mês. Porém, em empresas e obras que não têm esta preocupação, às vezes temos que pedir um prazo maior que o nosso, que é de quatro meses [...]". A prorrogação do prazo, ou não, caberá ao Superintendente Regional.

Os casos de embargos e interdições, em particular, são normalizados e com prazos definidos pela Portaria n. 40 (BRASIL, 2011b). Nesses casos, no entanto, o prazo de conclusão do ciclo torna-se dependente da correção das irregularidades identificadas pelos AIT e registradas em relatório técnico. Quando as exigências forem concluídas, a empresa deve apresentar requerimento solicitando a suspensão do embargo/interdição junto às unidades descentralizadas do MTE. Após o requerimento, o local paralisado deverá ser inspecionado novamente pelos AIT no prazo máximo de um dia útil contado a partir da data de protocolo (BRASIL, 2011b). Contudo, os engenheiros entrevistados relataram que raramente esse prazo vem sendo atendido. Um dos AIT considerou que o prazo é bastante curto e que dificilmente a informação é repassada no devido tempo, salvo quando é realizado diretamente pelas empresas. Na visão de outro AIT, nem sempre os agentes estão disponíveis para atender a essa demanda variável em curtíssimo prazo, visto haver outros compromissos previamente agendados. Nas visitas de retorno em que os AIT entendem que as exigências foram devidamente cumpridas, o termo de desembargo/desinterdição é emitido. Caso contrário, reinicia-se o subciclo a partir de um novo requerimento protocolado no MTE.

Em síntese, o ciclo de ação fiscal é efetivamente encerrado diante de três situações. A primeira acontece quando, após a visita de disparo, há constatação da inexistência de irregularidades. A segunda ocorre quando, após o AIT verificar a existência de RGI, houver regularização da situação conforme solicita o AIT. Por fim, a terceira ocorre quando, mediante notificações, elas são atendidas a contento, isto é, cumprindo-se as exigências nos devidos prazos. Ressalta-se que uma autuação é, por definição, suficiente para encerramento do ciclo fiscal na obra, embora aconteçam ações internas de continuidade do processo na SRTE ou na sede do MTE.

Com exceção da primeira situação, que é o bastante para o encerramento da ação fiscal, as demais situações isoladamente podem não ser o suficiente para o término de um ciclo de ação fiscal. Sendo assim, na existência de inadequações, os subciclos disparados, exceto o de autuação, como resultado da aplicação dos instrumentos de intervenção, devem ser finalizados, para que a ação fiscal na obra tenha, consequentemente, seu encerramento.

\section{Condições favoráveis à abertura de novos ciclos}

De acordo com os AIT entrevistados, diferentemente de outros setores econômicos, os ciclos fiscais na construção de edifícios tendem a se repetir com maior frequência e rapidez pelas características particulares desse setor. A maior visibilidade e controle social dos empreendimentos de construção como também a rápida mudança dos perigos são exemplos de fatores contribuintes para essa situação. Além disso, a fiscalização pode acontecer em diferentes estágios executivos da obra, desde a etapa de preparação do canteiro e fundações até as etapas de acabamento e desmobilização do canteiro. Contudo, segundo os AIT entrevistados, as ações fiscais ocorrem mais comumente nas fases em que a obra dispõe de um contingente maior de trabalhadores e processos considerados mais perigosos, tais como os revestimentos externos e as elevações da estrutura e alvenaria.

Nesse contexto, uma construção de edificações pode passar por um ou mais ciclos fiscais ou até mesmo não sofrer fiscalização. Diante da quantidade crescente de obras e do reduzido número de AIT, a abertura de novos ciclos em empreendimentos já fiscalizados é decorrente de situações especiais, aqui denominadas por condições favoráveis. Nesse sentido, determinadas características do empreendimento se configuram como condições favoráveis, particularmente pela possibilidade de se deflagrar um maior número de denúncias. Assim, quanto maior o prazo de execução do empreendimento, o impacto no entorno, o tamanho da obra (principalmente em termos de altura e número de trabalhadores) e visibilidade (localização em vias movimentadas ou centrais), maior será o potencial à geração de denúncias e, consequentemente, de abertura de novos ciclos.

Além disso, empresas que apresentam um histórico de descumprimento das legislações e que estejam executando grandes obras, tanto no tamanho quanto no contingente de trabalhadores, também são propícias a sofrer mais de um ciclo de ação fiscal. A organização atual das informações no MTE favorece a priorização das obras e das empresas resistentes em melhorar suas condições de adequação às legislações. Ademais, os resultados do primeiro ciclo de ação fiscal realizado em um empreendimento também podem se tornar uma condição favorável. Conforme os AIT, caso uma primeira ação fiscal detecte muitas irregularidades, há maior possibilidade de abertura de novos ciclos na obra. 


\section{Domínio de validade do modelo}

O modelo representa um ciclo básico, elementar e corriqueiro de ação fiscal, mas podem acontecer situações específicas que fogem ao domínio dele. Por exemplo, os AIT podem apenas autuar a empresa diante de inadequações, embora não seja uma situação comum na construção de edificações. O modelo é válido para empreendimentos de construção de edificações realizados principalmente por empresas formalmente instituídas, sejam executoras de obras públicas ou privadas. As pequenas obras de reformas particulares e atividades de construção informais se situam bem próximo das fronteiras de domínio do modelo proposto, especialmente pelo pequeno contingente de trabalhadores envolvidos. Por exemplo, um dos AIT destacou que, diante dessas tipologias de obras, "[...] tapa os olhos ou finge que não vê [...]". Contudo, havendo denúncias formais, as ações fiscais deverão acontecer.

Além disso, somente as ações fiscais formais e diretas (com inspeção em campo) estão em seu domínio. Na prática podem acontecer ações fiscais informais, particularmente quando há proximidade e contatos pessoais entre as partes envolvidas, e indiretas, ou seja, quando a empresa é obrigada a entregar documentos para análise dos AIT. A validade do modelo contempla somente trabalhadores celetistas e o que está em vigência nas legislações, principalmente na CLT (acordos coletivos, inclusive) e nas NR. Algumas decisões resultantes da participação do governo em comitês tripartites, como os Comitês Permanentes Regionais estabelecidos pelo NR-18, são orientativas à fiscalização, porém de caráter informal e não passíveis de exigência legal.

O modelo contempla exclusivamente decisões no âmbito do MTE, não discutindo decisões de outras esferas do poder público que possam intervir na execução dos empreendimentos. Dessa forma, não engloba, por exemplo, as ações do Ministério Público do Trabalho, que podem emitir os TAC (Termos de Ajustamento de Conduta) diante de riscos à coletividade de trabalhadores (RODRIGUES, 2002), como também as situações em que as empresas questionam judicialmente os embargos e interdições, obtendo algumas vezes liminares que garantem a suspensão das citadas sanções (BRASIL, 2010b). A modelagem foi baseada na coleta de dados específica à área de abrangência de uma única SRTE, o que pode limitar seu domínio, embora o serviço tenha diretrizes nacionais traçadas pela SIT. Os direcionamentos estabelecidos na Convenção 81 da OIT, ratificada pelo Brasil em 1987, também delimita o domínio do modelo.

\section{Considerações finais}

$\mathrm{O}$ artigo propõe um modelo para o processo de ação fiscal de segurança e saúde do trabalho na construção de edificações, que é representado graficamente por um fluxograma de processo descrevendo especialmente um ciclo fiscal em uma obra. Esse modelo pode ser descrito através de cinco etapas principais:

(a) planejamento da ação fiscal;

(b) visita inicial, que dispara o ciclo;

(c) resultados advindos da inspeção no empreendimento;

(d) término do ciclo; e

(e) condições favoráveis a aberturas de novos ciclos no mesmo empreendimento.

O modelo construído desempenha, especialmente, a função de organização e estruturação, à medida que a literatura é carente e fragmentada no que diz respeito a uma descrição sistemática e organizada desse processo. Nesse sentido, o modelo apresentado contribui com a estruturação dos elementos presentes na realidade das ações fiscais, segundo um esquema com ordenação lógica. Contudo, existe um domínio de validade para o modelo, o que não contempla, por exemplo, decisões que fogem da esfera do MTE, como as possibilidades de suspensão de embargos e interdições através de mandados judiciais. Dessa forma, o modelo é restrito na descrição da variabilidade real que um ciclo fiscal pode apresentar, inclusive com possibilidades de implicações negativas à segurança no trabalho.

Assim sendo, o modelo desenvolvido apresenta uma estruturação e descrição básica do processo de ação fiscal em operação na realidade brasileira, sem, contudo, se preocupar diretamente com a avaliação de sua eficácia, tampouco das condições de infraestrutura, seja em termos de recursos físicos ou de pessoal, para que as ações fiscais concretizem seus objetivos de prevenção aos acidentes. Todavia, foram identificadas boas práticas da fiscalização (por exemplo, uso de dois agentes nas visitas às obras e conversas informais com os trabalhadores), bem como práticas que necessitam ser reavaliadas, tais como a baixa incidência de fiscalizações em construções informais e de pequeno porte e no uso de listas de verificação. Além disso, os procedimentos de ação fiscal podem significar reflexos paradoxais à prevenção de acidentes, visto que, ao mesmo tempo em que a fiscalização pode encorajar 
inovações tecnológicas, o inverso pode ocorrer, pelo temor de que inovações estejam mais expostas a questionamentos.

A partir da modelagem proposta, novos estudos podem ser desenvolvidos, particularmente de caráter avaliativo ou comparativo. Por exemplo, podem-se avaliar os reais impactos das ações fiscais na prevenção de acidentes e diante das condições vigentes de infraestrutura do serviço brasileiro de inspeção do trabalho, como também a aprendizagem, em termos de armazenamento, análise e disseminação das informações, por parte das empresas e agentes de inspeção. Além disso, pode-se avaliar o modelo brasileiro de processo de fiscalização em comparação com modelos adotados em outros países.

\section{Referências}

BRASIL. Ministério do Trabalho e Emprego. NR 3: embargo ou interdição. 2011a. Disponível em: <http://portal.mte.gov.br/data/files/FF8080812DC 56F8F012DCD20B10A1691/NR-

03\%20(atualizada\%202011).pdf >. Acesso em: 9 abr. 2012.

BRASIL. Ministério do Trabalho e Emprego.

Portaria $n^{\circ}$ 40. 2011b. Disponível em: <http://portal.mte.gov.br/data/files/FF8080812DC 56F8F012DC8BB7A0946C7/Portaria\%20n\%20\% C2\%BA\%2040\%20(Embargo\%20e\%20Interdi\%C $3 \% \mathrm{~A} 7 \% \mathrm{C} 3 \% \mathrm{~A} 30)$ retificada.pdf $>$ Acesso em: 15 ago. 2013

BRASIL. Ministério do Trabalho e Emprego.

Portaria ${ }^{\circ}$ 546. 2010a. Disponível em: <http://portal.mte.gov.br/data/files/FF8080812C08 58EF012C11E8FA2D0FA1/p_20100311_546.pdf >. Acesso em: 30 set. 2012.

BRASIL. Embargo e Interdição: instrumentos de preservação da vida e da saúde dos trabalhadores. Porto Alegre: Ministério do Trabalho e Emprego, 2010b. 272 p.

BRASIL. Ministério do Trabalho e Emprego.

Decreto $n^{\circ}$ 5063. 2004. Disponível em: <http://portal.mte.gov.br/lumis/portal/file/fileDow nload.jsp?fileId=8A7C816A36A27C14013712BB 89AD051C>. Acesso em: 30 jul. 2013.

BRASIL. Ministério do Trabalho e Emprego.

Decreto $n^{\circ}$ 4552. 2002. Disponível em: <https://www.planalto.gov.br/ccivil_03/decreto/20 02/d4552.htm>. Acesso em: 30 set. 2012.

CARDOSO, A.; LAGE, T. A inspeção do Trabalho no Brasil. Revista de Ciências Sociais, Rio de Janeiro, v. 48, n. 3, p. 451-490, 2005.
KRAPAS, S. et al. Modelos: uma análise de sentidos na literatura de pesquisa em ensino de ciências. Investigações em Ensino de Ciências, v. 2, n. 3, p. 185-205, 1997.

MACHADO, J. M. A fiscalização do Trabalho Frente à Flexibilização das Normas Trabalhistas. Jus Navigandi, Teresina, v. 10, n. 644, 13 abr. 2005. Disponível em:

<http://jus.com.br/revista/texto/6599>. Acesso em: 29 set. 2012.

MARTINS, G. A. Teorias e Modelos nas Ciências Administrativas. In: SEMINÁRIOS EM

ADMINISTRAÇÃO, 6., São Paulo, 2003. Anais... São Paulo: FEA/USP, 2003.

MIRANDA, C. R.; DIAS, C. R. PPRA/PCMSO: auditoria, inspeção do trabalho e controle social. Cadernos de Saúde Pública, Rio de Janeiro, v. 20, n. 1, p. 224-232, jan./feb. 2004.

ROCHA, E. J. Avaliação de Embargos e Interdições na Construção Civil: estudo de caso em uma construtora e incorporadora de Porto Alegre. 2011. 92 f. Graduação (Trabalho de Conclusão de Curso de Engenharia Civil) Departamento de Engenharia Civil. Universidade Federal do Rio Grande do Sul, Porto Alegre, 2011.

ROCHA, L.; CAMBRAIA, F.; DONALD, R. As Ações de Prevenção de Doenças Ocupacionais em Empresas Construtoras de Edifícios: um estudo exploratório. In: CONGRESSO BRASILEIRO DE EXCELÊNCIA EM GESTÃO, 8., Rio de Janeiro, 2012. Anais... Niterói: UFF, 2012.

RODRIGUES, G. A. Ação Civil Pública e Termo de Ajustamento de Conduta: teoria e prática. Rio de Janeiro: Forense, 2002.

SAURIN, T. A. Segurança e Produção: um modelo para o planejamento e controle integrado. 312 f. Porto Alegre, 2002. Tese (Doutorado em Engenharia) - Programa de Pós-Graduação em Engenharia de Produção, Universidade Federal do Rio Grande do Sul, Porto Alegre, 2002.

SAURIN, T. A.; LANTELME, E.; FORMOSO, C. T. Contribuições Para Aperfeiçoamento da NR18: condições e meio ambiente de trabalho na indústria da construção. Porto Alegre:

Universidade Federal do Rio Grande do Sul, 2000. 140 p. Relatório de Pesquisa.

SILVA, V. A. E.; MATTÉ, M. H. Inspeção Sanitária em Creches: uma proposta de roteiro de inspeção. Revista de Direito Sanitário, São Paulo, v. 10, n. 2, p. 29-63, jul./out. 2009.

SLOVIC, P. The Risk Game. Journal of Hazardous Materials, v. 86, p. 17-24, 2001.

40 Silva Júnior, D. C.; Cambraia, F. B. 
UNITED STATES OF AMERICA. Department of Labor. Occupational Safety \& Health

Administration. OSH Act of 1970. 1970.

Disponível em:

<https://www.osha.gov/pls/oshaweb/owasrch.searc h_form?p_doc_type $=$ OSHACT\&p_toc_level $=0 \& p$ _keyvalue $=\& p \_s t a t u s=C U R R E N T>$ Acesso em:

21 ago. 2013.
VERA, A. A. Metodologia da Pesquisa

Científica. 7. ed. Porto Alegre: Globo, 1983. 223 p.

Didier Cardoso Silva Júnior

Departamento de Engenharia Civil, Centro de Ciências Exatas e Tecnologia | Universidade Federal de Sergipe | Av. Marechal Rondon, s/n, Jardim Rosa Elze | São Cristóvão - SE - Brasil | CEP 49100-000 | Tel.: (79) 2105-6700 | E-mail: didiercardoso@hotmail.com

\section{Fabrício Borges Cambraia}

Departamento de Engenharia Civil, Centro de Ciências Exatas e Tecnologia | Universidade Federal de Sergipe | Av. Marechal Rondon, s/n, Jardim Rosa Elze | São Cristóvão - SE - Brasil | CEP 49100-000 | Tel.: (79) 2105-6700 | E-mail: fabricio@ufs.br

\section{Revista Ambiente Construído}

Associação Nacional de Tecnologia do Ambiente Construído

Av. Osvaldo Aranha, $99-3^{\circ}$ andar, Centro

Porto Alegre - RS - Brasil

$$
\text { CEP } 90035-190
$$

Telefone: +55 (51) 3308-4084

Fax: +55 (51) 3308-4054

www.seer.ufrgs.br/ambienteconstruido

E-mail: ambienteconstruido@ufrgs.br 